\title{
Development and Delivery of On-line Upper Division Engineering Technology Courses: A Case Study
}

\author{
Sohail Anwar \\ The Pennsylvania State University, Altoona College \\ Jo-Ann Rolle and Altaf A. Memon \\ School of Business and Technology, Excelsior College
}

\begin{abstract}
With the advancement of Internet, on-line instruction is becoming popular in engineering education. Traditional and non-traditional colleges and universities are using a variety of instructional tools and techniques to deliver on-line courses to their students. Computer and telecommunication technological advances have provided alternatives to the traditional classroom setting.
\end{abstract}

The on-line learning environment facilitates a learner-centered approach to learning, with the learner as an active participant in the learning process. On-line learning provides a greater degree of learner control over the course materials. It also offers an enhanced level of interaction both in relation to the course materials themselves and in the opportunities presented for active learning through conferencing, discussion groups, and collaborative learning projects.

Excelsior College, located in Albany, New York, offers 31 different degree programs at the associate and baccalaureate levels in business, liberal arts, nursing, and technology and master's level degrees in liberal studies, business administration, and nursing. The college has been a pioneer institution in the distance learning. Numerous on-line courses have been recently developed by Excelsior College to serve the educational needs of its students. These courses cover a wide range of academic disciplines and can be delivered by a course management system known as WebCT, CD-ROM or directly through the Web.

This manuscript provides a detailed description of the WebCT-based upper-division engineering technology courses recently developed by the School of Business and Technology at the Excelsior College to fulfill the academic needs of students enrolled in its baccalaureate degree Electronics Engineering Technology program. These courses 
provide a virtual classroom with scheduled assignments, chat/whiteboards, dialogue with other students in the course via course e-mail, discussion boards, group activities, course content modules/lectures, quizzes, exams, and term projects/papers - all delivered online. The manuscript also provides information regarding the methods used in these courses to assess students' learning. Finally, the manuscript describes Excelsior College's future on-line education initiatives in the academic discipline of Electronics Engineering Technology.

\section{Introduction}

A variety of social, economic, and technological factors are converging to create increased demand for distance education. ${ }^{1}$ The rapid growth of access to the Internet and depth and breadth of information found therein has caused a rethinking of teaching methodologies within the educational community. ${ }^{2}$ Synchronous and asynchronous distance learning methods have become important components of undergraduate and graduate education. ${ }^{3}$ Distance education is becoming increasingly important to the mission of many institutions of higher education. ${ }^{4}$ As a result, non-traditional students now have enhanced academic opportunities in many academic fields, including engineering and engineering technology. Distance learning comes as a powerful tool to bring education to non-traditional students in a fast and modern way. ${ }^{5}$ The synchronous online education demands real time class access and availability; however, the Internetbased online asynchronous system of distance education does not have such requirements and is fast becoming a trend for both traditional and non-traditional students.

\section{Background}

Excelsior College with approximately 27,000 enrolled students, is one of the most respected distance learning institution in higher education. Founded in 1971 by the New York State Board of Regents as its external degree program and known in earlier years as Regents College, it was granted an independent charter in 1998. It changed its name to Excelsior College in 2001.

Always at the forefront of distance learning, Excelsior College has initiated several innovative programs in cooperation with business, industry, the military, and other academic institutions. The College introduced new academic programs incorporating industry-standard training received while on the job in fields as diverse as risk management and insurance, criminal justice, and nuclear engineering technology. To enable its students, all of whom are studying at a distance, to have online access to library facilities, the Excelsior College Virtual Library was introduced in 2000. In cooperation with the Sheridan Libraries at The Johns Hopkins University, Excelsior's students have access to the collection and services of one of America's most prestigious and extensive libraries.

Excelsior made its first venture into instruction at-a-distance with the introduction of its Master of Arts in Liberal Studies (1998) and Master of Science in nursing (1999) programs. Using the experience gained in these, the College has recently made a 
successful transition into the delivery of instruction in its undergraduate programs and now offers more than 100 courses at this level.

Excelsior College has been continuously accredited by the Commission on Higher Education of the Middle States Association of Colleges and Schools since 1977. Recognizing that college-level knowledge can be obtained in many ways, Excelsior provides access to many different avenues for earning college credit, focusing on what students know, rather than on where or how they learned it. Undergraduate credits are earned through a variety of accredited sources including for-credit exams, distance learning and online courses offered by Excelsior and other institutions; traditional campus-based courses; and military and corporate training. Excelsior's graduate degrees are also delivered online. Through these means, the college makes associate, baccalaureate, and master's degrees more accessible to busy, working adults.

Excelsior's associate, bachelor's and master's degree programs in nursing are accredited by the National League for Nursing Accrediting Commission. Its Bachelor of Science degrees in Electronics Engineering Technology and Nuclear Engineering Technology are accredited by the Technology Accreditation Commission of the Accreditation Board for Engineering and Technology. The American Council on Education (ACE) recognizes all Excelsior College Examinations for the award of college-level credit.

\section{Electronics Engineering Technology Program}

The ABET-accredited BS in Electronics Engineering Technology degree program offered by Excelsior College requires 124 semester hours of credits, including at least 60 credits in the arts and sciences component and at least 48 credits in the electronics engineering technology component. All the BS-Electronics Engineering Technology students must complete at least one course or examination in each of the following subjects constituting the Electronics Engineering Technology core requirements.
- $\quad$ Circuit Theory I
- $\quad$ Circuit Theory II
- $\quad$ Electronics I
- $\quad$ Electronics II
- Digital Electronics
- Microprocessors
- $\quad$ Systems
- $\quad$ Electronic Communications or Data Communications Systems
- $\quad$ Computer Programming

In addition to the Electronics Engineering Technology core requirements, students must complete a 3-credit Integrated Technology Assessment (ITA) requirement.

The On-line Courses in the BS-Electronics Engineering Technology Program

Before September 2004, students enrolled in the BS-Electronics Engineering Technology Program offered by Excelsior College had to demonstrate their college-level knowledge 
and competencies in the academic field of electronics engineering technology only through the submission of transcripts from regionally accredited colleges/universities or through written/performance examinations. In September 2004, the following upper division on-line courses in the BS-Electronics Engineering Technology were launched:

1. ELEC 301: Digital Electronics (4 credit-hours)

2. ELEC 302: Microprocessors (4 credit-hours)

3. ELEC 495: Integrated Technology Assessment (3 credit-hours)

The length of each of the above mentioned electronics engineering technology courses is 15 weeks. In January 2005, a total of five on-line upper-division electronics engineering technology courses were launched. In addition to ELEC 301, 302, and 495 (listed above), the following courses were offered:

1. ELEC 321: Control Systems (3 credit-hours).

2. ELEC 330: Electronic Communications (4 credit-hours).

Once again, the length of each of the above-mentioned on-line courses is 15 weeks.

Format of Excelsior College's On-line Courses

A standard template is used for each of the above mentioned on-line WebCT-based courses. The first page of any course is considered the "Homepage". It is basically the controller for the course that students will use. There are 2 sections of the Homepage. The section to the left is called the Course Menu and the section to the right is the Course Homepage.

The course homepage gives the student the title of the course. The course homepage is condensed to as little number of course icons as possible. By limiting the modules on the homepage, the instructor/faculty can use the selective release feature. This feature allows instructors to open up sections of the course at different times. For example the instructor may want to allow the students to view the course information and calendar, but block the actual tools and course data. By using the selective release function, they can. By limiting the number of icons on the homepage, one makes this administration more efficient. It also gives students an easier way to navigate their course.

The icons that are made available on the homepage are as follows:

- Information about this course (or Course Information)

- Course Content Modules

- Course Tools (Includes glossary as well)

- Calendar (All deadlines and due dates included)

- Students Tips 
In addition to the above icons, announcements and messages can be posted in the upper and/or lower text block on the homepage. Under the course information, following items are included:

- Welcome

- Course Introduction (Course title, number, brief description, and required materials)

- Instructor Bio

- Contact Information

- Basic Course Information (Course title, number, prerequisites, start and end dates, etc.)

- Course Syllabus

- Systems Information (System Requirements and Tech Support Information)

- Policies (Excelsior College policies of Academic Honesty, Electronic Use, etc.)

Under the syllabus, following items are addressed:

- Detailed Course Description

- Course goals, objectives/outcomes

- Required and recommended Course Materials

- Library and Reserve readings

- Course Outline with due date schedule

- Procedure for communicating with the faculty

- Course Assessment (Exams, projects, discussions, quizzes, etc.)

- Grading Policy (weights and Excelsior grading scale)

- Course Policies (e.g. honesty, plagiarism, late submissions, effective writing, etc.)

- Other Course Instructions (WebCT Institutional bookmark: Excelsior College Virtual Library, Electronic Peer Network, Bookstore, etc.)

Example of a Course

\section{ELEC 321 Course Syllabus}

\section{Course Number:}

ELEC 321

Course Title:

Control Systems

\section{Brief Course Description:}

Introduction to control of mechanical and electrical systems; study of open and closed feedback; servo mechanisms; principles of digital control.

\section{Course Prerequisites:}

1. Understanding of DC and $\mathrm{AC}$ theory, electronics, and digital principles. 
2. Algebra, trigonometry, and basics of differential and integral calculus.

3. A working knowledge of the use of one or more computer software packages for technical problem solving appropriate to the electronics technology discipline.

\section{Course Start Date:}

January 3, 2005

\section{Course End Date:}

April 29, 2005

\section{Required Text:}

Nise, Norman S. Control Systems Engineering, Fourth Edition. Wiley, 2004.

Please note that there is a Web site available for this course, at www.wiley.com/college/nise, which has some problem solutions and MATLAB files to help you understand the course material.

\section{Supplemental Reading List:}

- Dorf and Bishop, Modern Control Systems, $9^{\text {th }}$ Edition, Prentice Hall, ISBN: 0-130-30660-6

- Dorsey, John F., Continuous and Discrete Control Systems with CD Rom, 2002, McGraw-Hill, ISBN: 0-072-50500-1

- Johnson, Curtis D., Process Control Instrumentation Technology, $7^{\text {th }}$ Edition, Prentice Hall, ISBN: 0-130-60248-5

- Stefani, Shahian, Savant and Hostetter, Design of Feedback Control Systems, $4^{\text {th }}$ Edition, Oxford University Press, ISBN: 0-195-14249-7

- Webb and Reis, Programmable Logic Controllers: Principles and Applications, $5^{\text {th }}$ Edition, Prentice Hall, ISBN: 0-130-41672-X

- Zak, Stanislaw, Systems and Control, Oxford University Press, ISBN: 0-195-15011-2

\section{Internet Browser/software requirements:}

All students are required to have access to the following computing resources:

1. A reasonably up-to-date personal computer that runs Windows 98 or later.

2. Availability to MS-Office, especially Word.

3. Capability to open and display PDF files.

4. A working and reliable Internet connection with a current Web browser.

5. An e-mail account.

\section{Detailed Course Description:}

Automatic feedback control systems play a vital role and have a major impact on modern technological systems. The applications of control systems cover a very wide range. Microprocessors and microcontrollers have added a new dimension to 
the capability of control systems. New applications for automatic control systems are continually being discovered.

In this course, students will study analysis and design of classical feedback control systems. They will learn how to model continuous-time control systems and how to analyze the performance of feedback control systems.

The concepts and techniques of control systems analysis and design will be developed and applied toward a variety of electrical and mechanical processes. Therefore, this course will be useful for a variety of engineering disciplines and will illustrate the unity of a wide range of topics falling within the domain of control engineering.

\section{Course Goals:}

This course strives to attain the following goals:

- Introduce the fundamentals of feedback control systems

- Develop ability to model continuous-time control systems in the frequency domain and in the time domain

- Determine the output response of a feedback control system

- Analyze the stability of a feedback control system

- Analyze feedback control systems for steady-state errors

- Design feedback control systems using multiple techniques

\section{Course Outcomes:}

At the end of this course students should be able to:

- model continuous-time control systems in the frequency domain using transfer functions and block diagrams

- model continuous-time control systems in the time domain using state equations

- determine and describe the output response of a feedback control system

- analyze the stability of a feedback control system

- design feedback control systems using multiple techniques

\section{Grading:}

Grading will be on a point basis with the total number of points for the course being 300 points as follows:

1. Homework (10 points each)

This course studies in detail the concept of feedback as a critical part of any system. Assigning work to the students provides a dual feedback mechanism. First, the assignment of homework tells the students what concepts they need to study in deeper detail or consult with the instructor, at the same time that gives them the opportunity to practice what they have learned in the classroom. Second, it provides the instructor with feedback on how the concepts are being developed among the students. For these reasons, and given the dynamic mechanism involved in homework, its timely development is critical to its success. 
Seven homework assignments will be given resulting in a total of $7 @ 10$ points=70 points. Homework which is substantially completed will earn ten points, while incomplete homework will receive partial credit. Missing homework will earn zero points.

2. Quizzes (20 points each)

Four quizzes will be given. Two quizzes will be given before the mid-term exam and two after the mid-term. The quizzes will account for a maximum of 80 points (4@20 points).

3. Mid-term Exam (50 points)

A mid-term exam will be administered at the end of Module 7.

4. Final Exam (100 points)

A comprehensive final exam will be administered during week 17 (4/25/05$5 / 1 / 05)$

\section{Letter Grade:}

Course letter grades will be assigned according to the following scale:

\begin{tabular}{|c|c|}
\hline Letter Grade & Percentage Range \\
\hline A & $90 \%$ and above \\
B & $80 \%-89 \%$ \\
C & $70 \%-79 \%$ \\
D & $60 \%-69 \%$ \\
F & Below $60 \%$ \\
\hline
\end{tabular}

\section{Academic Integrity:}

Definition and expectations: Academic integrity is the pursuit of scholarly activity in an open, honest and responsible manner. Students should act with personal integrity, respect other students' dignity, rights and property, and help create and maintain an environment in which all can succeed through the fruits of their efforts.

Academic integrity includes a commitment not to engage in or tolerate acts of falsification, misrepresentation or deception. Such acts of dishonesty violate the fundamental ethical principles of the University community and compromise the worth of work completed by others. 
To protect the rights and maintain the trust of honest students and support appropriate behavior, reasonable steps to anticipate and deter acts of dishonesty in all assignments.

\section{WebCT-based Course Teaching}

For a successful on-line teaching experience, it is essential that student-faculty interaction occurs regularly and in a timely fashion. The Excelsior College on-line teaching faculty is encouraged to include practices such as weekly activities, a variety of assessment tools, announcements, feedback, relevant discussion topics, and timely posting of grades in the on-line course design.

For an on-line course, all course work must be done within the confines of WebCT. No coursework is to be communicated, submitted, and reviewed outside the WebCT. Private e-mails are to be used only for personal communication that cannot be discussed within the course. The main purpose for this policy is to retain course work in one place rather than scattered around.

When an on-line course is completed during a 15-week term, a copy of the course is stored for at least 5 years. This way if there is any question regarding student grades, the grades can be retrieved.

\section{On-Line Course Evaluation}

A course evaluation template is provided to students in each on-line course for course evaluation. The template consists of 27 questions. Twenty four of these questions employ a rating scale ranging from 1 to 7 . A rating of 1 denotes "strongly disagree" while a rating of 7 represents "strongly agree". The remaining three questions solicit a subjective response from students. All the twenty seven questions are listed below:

1. The grading policy was made clear at the beginning of the course.

2. Initial instructions did not clarify the course objectives and content at the beginning of the course.

3. Interacting with other students helped me meet the learning objectives of this course.

4. Engaging with other students in course related activities (e.g., discussions, team projects, etc.) made me feel like I was part of a learning community.

5. The instructor did an excellent job interacting with students using available technology (e.g., email, discussion boards, chat).

6. I understood what I needed to do to complete my assignments.

7. Graded assignments were not related to the course objectives.

8. Assignments stimulated my interest in the topics covered in this course.

9. Graded assignments for this course were returned quickly.

10. The time given to complete assignments allowed me to do my best work.

11. The discussion questions did not help me learn the content of the course.

12. The feedback I received on my assignments from this course helped me perform better on subsequent assignments.

13. The readings for this course were not presented in a logical order. 
14. The readings for this course stimulated new thinking about course content.

15. The readings for this course helped me meet the learning objectives of the course.

16. The instructor conducted this course in a way that accomplished the stated objectives.

17. The instructor for this course responded to questions in a timely manner.

18. The instructor for this course did not seem interested in helping me learn the material.

19. The instructor's feedback helped me learn.

20. The course schedule was not flexible enough to meet my needs.

21. I would recommend this course to others.

22. Overall I was very satisfied with this course.

23. Before starting my online course(s) I received sufficient information about registration requirements and prerequisites.

24. Before starting my online course(s) I received sufficient information about student support services.

25. WebCT is the name of the software program used to administer this course. Did you have any problems using WebCT that you would like to share? If yes, what were they?

26. If you felt this course faired poorly on any of the above dimensions (or any that were not included above), what could we change to improve the course?

27. Do you have any additional comments you would like to share with us?

\section{Conclusion}

The enrollment figures for the upper-division electronics engineering technology on-line courses delivered by Excelsior College during January 2005 15-week term (January 3, 2005 - April 29, 2005) are listed below:

ELEC 301: Digital Electronics - 11

ELEC 302: Microprocessors - 5

ELEC 321: Control systems - 7

ELEC 330: Electronic Communications - 8

ELEC 495: ITA - 5

The above-mentioned on-line courses will be offered again during the May 200515 -week term (May 2, 2005 - August 26, 2005). It is expected that as more and more Excelsior College students realize the benefits of on-line courses, the enrollment in these courses will increase. It is Excelsior College's goal to maximize the students' ability to succeed academically.

Bibliography

1. Ssemakula, M. "Development of a Fully Online Course in Engineering Economic Analysis", Proceedings of the 2004 ASEE Annual conference. Session 3549. Available CD-ROM

2. Easton, R., and Stratton, J. "Distance Learning: Facts, Failures, Foibles, and the Future," Proceedings of the 2004 ASEE Annual conference. Session 1648. Available CD-ROM

3. Ko, Y., Duman, T., and Spanias, A. "On-line Laboratory for Communication Systems Using J-DSP," Proceedings of the $33^{\text {rd }}$ ASEE/IEEE Frontiers in Education Conference, 
November 5-8, 2003. Available CD-ROM

4. Salehfar, H., Watson, J., Johnson, A., Krenelks, L., McCartney, T., and Faul, D. "Using Information Technology to Offer Undergraduate Distance Engineering Programs Online," Proceedings of the 2004 ASEE Annual Conference. Session 2432. Available CD-ROM

5. Brito, C.R., and Ciampi, M. "Distance Learning Designing New Relations in Engineering Education." Proceedings of the $34^{\text {th }}$ ASEE/IEEE Frontiers in Education Conference. October 20-23, 2004. Available CD-ROM.

\section{Biography}

\section{SOHAIL ANWAR}

Sohail Anwar holds a Ph.D. degree in Industrial and Vocational Education from the Pennsylvania State University and a M.S. degree in Electrical Engineering from the University of Texas at Arlington. He completed additional graduate coursework in control theory and applied mathematical sciences at the University of Texas at Arlington. He is currently serving as an associate professor of Engineering and the Program Coordinator of Electrical Engineering Technology at The Pennsylvania State University, Altoona College. Since 1996, he has also served as an invited professor of Electrical Engineering at IUT Bethune, France.

\section{ALTAF A. MEMON}

Altaf Memon holds MSCE, MPW, and Ph.D. degrees from the University of Pittsburgh, Pittsburgh, Pennsylvania and an M.Eng. degree in Environmental Engineering from the Asian Institute of Technology, Bangkok. He is currently serving as the Associate Dean of the School of Business and Technology at the Excelsior College, Albany, New York.

\section{JO-ANN ROLLE}

Jo-Ann Rolle holds a Ph.D. degree in Economics from the Howard University and a M.A. degree in Economics from the Southern Illinois University, Edwardsville. She is currently serving as the Dean of the School of Business and Technology at the Excelsior College, Albany, New York. 